Revista de la red interuniversitaria de estudios sobre las literaturas rioplatenses contemporáneas en Francia

$9 \mid 2013$

Homenaje a Ana María Barrenechea

\title{
Macedonio poeta recienvenido
}

Jorge Monteleone

URL: http://journals.openedition.org/lirico/1134

DOI: $10.4000 /$ lirico. 1134

ISSN: 2262-8339

Editor

Réseau interuniversitaire d'étude des littératures contemporaines du Río de la Plata

Referencia electrónica

Jorge Monteleone, « Macedonio poeta recienvenido », Cuadernos LIRICO [En línea], 9 | 2013, Puesto en línea el 01 septiembre 2013, consultado el 02 mayo 2019. URL : http://journals.openedition.org/ lirico/1134; DOl : 10.4000/lirico.1134

Este documento fue generado automáticamente el 2 mayo 2019.

\section{(c) $(1) \Theta \Theta$}

Cuadernos LIRICO está distribuido bajo una Licencia Creative Commons Atribución-NoComercialSinDerivar 4.0 Internacional. 


\title{
Macedonio poeta recienvenido
}

\author{
Jorge Monteleone
}

\author{
Para mi maestra Ana María Barrenechea, \\ que también practicaba el humorismo de la nada
}

1. No hay como la literatura para transformar la voluntad de ausencia y todo acto de la más pura negatividad en una presencia incesante y una paradojal realización; no hay como la literatura para aniquilar la persona y hacerla retornar como un muerto vivo o un mito viviente : il morto chi parla. Basta que Cesare Pavese escribiera en su diario: “(...) tutto questo fa schifo. Non parole. Un gesto. Non scriverò più" ("Todo esto da asco. Ni una palabra. Un gesto. No escribiré más") y se matara de un escopetazo en una pieza de hotel en Turín para que esa escritura no cese jamás ; basta que Kafka ordenase quemar sus libros para que sean salvados de la hoguera; basta que Arthur Rimbaud abandonase la poesía para que la poesía lo mitifique y lo suspenda en el tiempo como si jamás cesara de escribir. Macedonio Fernández desdice su Yo como No-Existente Caballero y mina la autobiografía, para que sus lectores lo multipliquen y lo nombremos ahora mismo con abrumadora insistencia y hasta su frágil figura desvanecida nos resulte tenazmente próxima, familiar, casi parental. Me refiero al "conocido escritor oral Macedonio o Marcelino Rodríguez o Fernández, inconfundible notoriedad de la literatura contemporánea cuya celebridad crece día a día, pues todavía no se sabe lo conocido que es, en llegar al público" (Macedonio Fernández 1966 : 128). Acaso sobre todo porque la compleja autoreflexión del autor jamás se separa de la proyección misma del lector, negando toda precedencia o jerarquía. En un texto, finalmente no incluido en Museo de la Novela de la Eterna, bajo el título "El autor también habla" se lee: "Yo, el autor, soy principalmente público aun ahora en la publicidad. (...). Así pues, a medida que escribo, indago y espero sucesos, como el lector" (Macedonio Fernández 1993 : 269). Obra de "altrui-existencia", donde el autor se sustenta ausente vitalizando a sus lectores futuros, es decir, a nosotros mismos. La incesante sustracción de la figura de autor es, como aquí mismo queda demostrado, la incesancia de la proyección de lectores que desde hace décadas, e incluso sin leerlo, hablan, hablamos de Macedonio : "déjeseme tener una sola inexistencia en mi novela : El No-Existente-Caballero; (...), el único no existente personaje, funciona por contraste como vitalizador de los demás" (1993 : 270). Esos otros personajes son las formas vacías que como lectores realizamos y encarnamos, para que la Posteridad dé una vida (nueva) a 
esa laboriosa y anarquista inexistencia que de ese modo subrepticio ingresa en el Ser del Belarte.

Pero el logos de esa literatura conformada en la inexistencia del autor que se oblitera como documento de vida, se funda precisa y paradójicamente en un crucial hecho autobiográfico: la imprevisible muerte de Elena de Obieta, la esposa de Macedonio Fernández, el 28 de mayo de 1920. Una y otra vez ese hecho se menta, explícita o implícitamente, como origen, destino y sentido de toda su escritura. Por cierto, Macedonio nos obliga siempre a infundamentar todo acto, a sustraerlo de cualquier carácter fundacional y esencialista y originario para volverlo diferido : allí todo lo que comienza no sigue o el comienzo se multiplica en discontinuidad y fragmentación y aún la totalidad es pensada como un "Todo" de "No ser", Todo y Nada. Por ello su lugar -topos y a la vez tópico- es el de la espera : la novela de la Eterna es concebida como

un hogar para la no existencia en que necesita hallarse Deunamor, el No-Existente Caballero, para tener un estado de efectividad (...) mientras espera, y cuando llega de vuelta de la muerte su amada, que él llama la bella muerta, es decir que embelleció a la muerte con su sonreír, en el morir y que sólo tuvo muerte de Beldad : la hecha sólo de separación, de ocultación, la muerte que engendra toda la belleza de la Realidad : la que separa amantes, pues otra muerte no hay. (22. El subrayado es mío)

Pero esa espera definió también la situación misma de la literatura de Macedonio : el escritor Recienvenido que espera su propia venida y que asimismo la espera en cada lector, al cual le dice : "leerás más como un lento venir viniendo que como una llegada" (Macedonio Fernández 2010: 133). Cada uno de los textos de Macedonio, como Recienvenido y No-Existente Caballero, creó un lugar para tener un estado de efectividad en ese venir viniendo. Por ello mismo, definir a Macedonio como un vanguardista es a la vez falso y verdadero. La vanguardia ejerce un voluntarista acto de futuridad y afirmación en el comienzo como proyección de novedad, desde el "il faut être absolument moderne" (hay que ser absolutamente moderno) de Rimbaud hasta el "Make it new !" (¡Hazlo nuevo !) de Pound. Pero en Macedonio la marca del comienzo, que es radical, a la vez se infundamenta en una continuación... de la Nada : de la novela que comienza se prevé una novela que no sigue o que prolifera en prólogos hasta un prólogo final. Los textos de Macedonio esperan para ser leídos y ni siquiera se escriben como una obra compuesta o se corresponden con su propio tiempo de arribo : "se trata de un llega-tarde como autor lo que es temprano donde no se lo espera-", escribió (1993 : 304. Subrayado mío). Todos sabemos, como explicaba Adolfo de Obieta en las compilaciones de los años sesenta, que los libros de Macedonio eran considerados borradores y "no resultaron de un acto cuidadosamente personal de construcción, sino más bien de la simpatía de amigos recopiladores, seleccionadores $u$ ordenadores de textos" (A. de Obieta en Macedonio Fernández 1967 : 5). Podría afirmarse que la autoría misma que lo sostiene como persona jurídica en el nombre y la firma se halla en entredicho por su estatuto ficcional de personaje. Y no es irónico sino sintomático que la tesis de doctorado del Dr. Macedonio Fernández lleve por título "De las personas" y que, asimismo, No toda es vigilia la de los ojos abiertos se presente como "Arreglo de papeles que dejó un personaje de novela creado por el arte, Deunamor el No Existente Caballero, el estudioso de su esperanza” (1967 : 73 ).

¿Qué espera esa esperanza? El poema "Suave encantamiento", que Evar Méndez sindica como precursor del ultraísmo al publicarlo en un número de la revista de la vanguardia Martín Fierro hacia 1925, había sido publicado veinte años antes, en 1904, pero ese carácter de adelantado obra mediante la irrisión de la causalidad y la cronología, no sólo porque un breve número de poemas junto a otros cientos de páginas se publicaron 
póstumamente, sino porque lo póstumo también forma parte de su propia formulación en tanto condición de la espera. Y creo, por ello mismo, que uno de los tres géneros puros de su Estética o Belarte, la Metáfora o Poesía -ese género que, como algunos comentaristas afirman, Macedonio estuvo a punto de no incluir en la serie, o cuya relativa pureza quiso afirmar diferenciándolo de todo carácter rítmico para constituirlo como "Poemática del Pensar"- es un núcleo irradiante de su literatura precisamente porque no se halla en el centro sino como una excentricidad de su escritura. Una lírica extremista en la cual no hay un sujeto lírico ni escindido ni pluralizado, pero tampoco hay una impersonalidad, sino una voz que se nombra en coalescencia con la Amada y dice "soy Ella, / soy Su ausencia, soy lo que está solo de Ella" (2010 : 104). Lírica en la cual el Poeta deviene No existente todavía, poeta inminente de poema latente y por venir en su puro llegar tarde; poeta diversificado y negado en el juego de reverberaciones de las personas poéticas : "Todavía no es poeta, no soy poeta, no hay poeta, pues que esto no se sabe. Hasta ahora, pues, solo vivimos" (1966:270). Y ese núcleo irradiante proviene, como ya sabíamos, de aquel hecho biográfico y vital que vacía la vida : la muerte en 1920 de la bella Elena, transfigurada en el poema "Elena Bellamuerte" donde Muerte es Beldad. Inicialmente el poema se llamó de un modo más literal: "Elena de Obieta Bellamuerte". ${ }^{1}$ La anécdota, que entre otros divulgó César Fernández Moreno y corroboró su hijo Adolfo de Obieta, de que ese poema, escrito en 1920, fue descubierto veinte años después de ser escrito por Macedonio guardado en "una absurda caja de bizcochos" Canale y que, además, hay una segunda versión en prosa del poema, llamada "Otra vez", como si la mujer retornara otra vez en imagen, a la espera de ser mirada en una nueva vigilia eterna, todo ello conviene por completo a la poética de la espera y el ocultamiento, que el mismo poema formula en sus versos finales : “iCuándo será que a todo amor alzado / servido su vivir, a boca chocada y rota última copa / pruebe otra vez, la eterna Vez del alma / el mirar de quien hoy solo el ser de Esperada tiene / cual solo de Esperado tengo el ser !" (2010: 103). Y en "Otra vez" se lee : "la Espera es de amor amiga : fue de Ella convidarme a la espera al dar ella, y no yo, el paso de Ausencia" (2010: 111).

5 Creo que no se ha reflexionado lo suficiente sobre la poesía de Macedonio. Hay recientes y luminosas excepciones en los extensos artículos de Mariano Calbi (2007) y de Juan Rigoli (2007) en el volumen 8 al cuidado de Roberto Ferro de la Historia Crítica de la Literatura Argentina dirigida por Noé Jitrik, que por su alcance, considero fundacionales de esa reflexión, además de todas las menciones de rigor en la crítica previa, incluyendo el capítulo que le dedica el propio César Fernández Moreno en Introducción a Macedonio Fernández (1960) o las reflexiones oblicuas que la presuponen, como las Germán García (2000 [1975]) sobre la escritura o las de Diego Vecchio (2003) en sus vínculos con la filosofía, entre muchas otras. Esa breve obra poética que, en fin, prologó en una edición póstuma publicada en la editorial Guarania de México en 1953 Natalicio González, llegó a ser ordenada por el autor -como lo corroboró Adolfo de Obieta- y tuvo otras reediciones en Argentina y en España, requiere una exégesis muy pormenorizada por sus alcances. ${ }^{2}$ Por ello, estas líneas son una mera declaración voluntarista, una digresión declarativa que afirma una tenue hipótesis provisoria: que el lugar de la poesía en la literatura de Macedonio es el sitio de lo neutro.

6 La poesía de Macedonio ocupa ese lugar de lo neutro porque se dirime en ese sitio que es indecidible respecto de una disyunción, pero sin anular o superar la tensión entre dos polos como un tercer espacio dialéctico : Neutro es Ne-uter, ni lo uno ni lo otro, pero sí, como afirmaron tanto Maurice Blanchot como Roland Barthes, posee un carácter 
dislocador en lo espectral, en el duelo de un fantasma. El primero afirma que Neutro "sería el acto literario que no es ni de afirmación ni de negación y que (en un primer momento) libera el sentido como fantasma, obsesión, simulacro de sentido, como si lo propio de la literatura fuese ser espectral" (Blanchot 1970 : 477). El segundo afirma, al introducir en su reflexión el episodio de la muerte de su madre ("El hilo cortante del duelo"), que la forma esencial de lo Neutro es una protesta contra la muerte :

Consiste en decir : me importa poco saber si Dios existe o no, pero lo que sé y lo que sabré hasta el final es que no debería haber creado al mismo tiempo el amor y la muerte. Lo Neutro es el No irreductible : un No como suspendido ante la dureza de la fe y de la certidumbre, e incorruptible por una y otra. (Barthes $2004: 60$ )

$7 \quad$ Y aquí estamos en la plena disposición de Macedonio poeta : porque, en primer lugar, el carácter neutro de su poesía consiste en una radicalización a la vez del fantasma de la amada y la protesta y anulación de la muerte transfigurada en la ficción del poema, donde Elena es "la niña del fingido morir" y donde la muerte es negada por el amor : "No eres, Muerte, quien por nombre de Misterio logre hacer pálida mi mente cual a los cuerpos haces. Nada eres y no la Nada. Amor no te conoce poder y pensamiento no te hace incógnita" (Macedonio Fernández 2010 : 110). Y porque, en segundo lugar, el acto literario supremo de constituir al tú de la Eterna en una mística amorosa que es asimismo la crítica del Yo, sitúa el lugar del amor como Pasión que no es disyunción sino un espacio otro en un ser Dual -es decir, un espacio que afirma en el Dos el Uno múltiple, como una manifestación de lo Neutro- : "Yo sigo a la Pasión, que tiene toda certeza y cuyo dogma es : 'Nada me aminore; sólo yo soy preciosa en el Ser, sólo en mí hay un Yo; no el mío sino el de Ella, dice el Amante ; no el mío sino el de Él, dice la Amada"'.

Así, la metafísica de Macedonio es también estética : el mundo es un almismo ayoico. Según esa noción el Ser, todo lo que existe, se identifica con estados de sensibilidad -lo sentido, la afección-- Sólo hay estados: sentimientos, sensaciones de dolor o de placer, e imágenes. En consecuencia, no hay mundo material, ya este es un sueño de la afección, la plenitud inmediata de todo el ser en lo sentido: hay sólo imaginación e ideación (imágenes-signos o signos de imágenes). Puesto que nada que no ocurra en la sensibilidad existe, se disuelven los polos del sujeto y del objeto, del yo y del tú, en esa serie psicomaterial de estados, continua, de creación constante y duración homogénea. De allí surge la negación del yo y de la materia, de la extensión y del espacio, del tiempo y de la causalidad. Por ello la Altruística o Pasión, afirma Macedonio, es la idoneidad suprema del Ser. La Pasión es el estado místico perfecto, por el cual se ama a la persona que sólo en apariencia reside en otro cuerpo y que finalmente se reconoce como propia en una fusión psíquica que, sin embargo, no anula a los amantes. De ello se deriva la negación de la muerte. La muerte es, entonces, ocultación : un estado transitorio. Si los amantes deben desligarse de la muerte, es el arte el que debe resolver en la imagen y en la forma la tragedia del amor violado por la ocultación y en peligro de cesar por el olvido. Su estrategia consiste en crear en el lector el momento en el que acepta esa contingencia del dolor, la imago de lo ausente como espera de una mirada por venir. La poesía es por ello un acto de Belarte Conciencial, donde se manifiesta lo neutro, ne-uter, ni una cosa ni la otra : ni vida ni muerte, ni tú ni yo, ni ausencia ni presencia, ni momento ni lugar, ni uno ni otra sino entre Dos, el lugar indecidible del Todo-Misterio que no se nombra en la espera de lo eterno :

Palabras terminan

Más allá de ti, Muerte, fuimos con Ella. 
Vueltos de la Muerte vivimos.

Y yo ahora solo. Ella tornada a ti.

Y después de ti me espera.

Deidad, ni Cielo, nombrar no lograron

al Misterio y quitárnoslo.

Tenemos Misterio que ni Deidad ni Cielos interponen ;

su ademán distrayente no quisimos.

Sólo el Todo-Misterio indisminuido

en que nos sabemos eternos.

Desdeñamos distracción de leyendas.

Sólo un Misterio que no se nombra.

Sin momento ni lugar. (2010: 109)

Por ello la mirada -y toda la correlación de tesis y antítesis de los ojos abiertos o los ojos cerrados, que conllevan las de vigilia y de ensueño, así como las de olvido y memoria- es la facultad privilegiada, tanto como la tarde o la siesta es el tiempo que sustenta este imaginario de lo neutro. "Profundos y plenos / cual dos graciosas, breves inmensidades / moran tus ojos en tu rostro como dueños", comienza el célebre poema "Suave encantamiento", que finaliza: "Ojos que se abren como las mañanas / y que cerrándose dejan caer la tarde". Afirmar que los poemas como éste, previos a "Elena Bellamuerte", son románticos, es irrelevante respecto de su específica prefiguración: esos textos escritos entre 1901 y 1904 son del todo congruentes no sólo con la metafísica incipiente que Macedonio redactaba por entonces y que tendría su desarrollo posterior, sino también como variaciones rítmicas de los textos de la Poemática del Pensar que escribiría dos décadas después de "Elena Bellamuerte" : la playa del suspiro único o del sueño único, los ojos que se abren como mañanas y que al cerrarse dejan caer la tarde y la siesta que gravita donde el tiempo fulminante se detiene o el verso final de la extraordinaria presciencia de 1912, "Hay un morir": "esto es Muerte : Olvido en ojos mirantes" (2010: 106). Esos poemas "iniciales" son, en verdad, la previa resonancia de una causalidad invertida que fuga a poemas escritos mucho después, tales como "Poema al astro de luz memorial" o "Poema de trabajos de estudios de las estéticas de la siesta" ; "Fantasma de la Siesta Evidencial. / Exaltación de la Vigilia de la Presentación-Natura que hace dentro a los Ojos sombras de reverberación".

El lugar neutro de la Metáfora o Poesía de Macedonio también se ocupa respecto de la propia Belarte, porque no es un término tercero, o una alternativa, sino una latencia entre los dos grandes géneros que explícitamente admite: la Humorística Conceptual y la Novela o Prosa del Personaje. César Fernández Moreno asegura que la poesía tout court no tiene lugar en la trivia, "porque la poesía no es belarte sino vida" y sólo una Poemática del Pensar sería Belarte. Juan Rigoli recuerda que para Macedonio la poesía es "dudosamente artística" y alguna vez estuvo tentado de excluirla. Lo que sí excluyó -y con ello efectivamente también excluía una vasta textualidad- es lo que llamaba "Versificación" porque renegaba con énfasis del uso del "compás", es decir, de la métrica y la rima : "El compás es tan antimusical como antiliterario, porque es antiviable y antivital -escribió-. Excluyo la versificación como ajena al arte literario y a todo arte, porque además de pretender ser demasiadas artes juntas, no es ni Prosa ni Música, pues el compás y la rima son antimusicales" (Macedonio Fernández 1974 : 250). Sin embargo la poesía y la epifanía de "Elena Bellamuerte" obran como una matriz de sentido que convoca y relanza todas las orientaciones significativas de la escritura de Macedonio, desde No toda es vigilia la de los ojos abiertos hasta el gran proyecto de la Novela de la Eterna y aun toda la teoría del Arte. Por ello el corpus mismo de su poesía nunca termina de definirse: hay pasajes en los 
textos teóricos que guardan estrecha relación con los poemas y asimismo los poemas pueden leerse teóricamente ; hay textos claramente poéticos que los editores de la Eterna decidieron dejar al margen pero formaban parte de su órbita; hay, en fin, poemas anteriores a "Elena Bellamuerte" citados enteramente en la trama de Adriana Buenos Aires. Además, la elección de la sintaxis como el otro ritmo que gobierna con alta complejidad el sentido del poema en lugar de la métrica y la rima, abrió a la tradición conceptual de la poesía argentina un carácter singularísimo y acaso sin precedentes en la poesía de Hispanoamérica : en ese carácter también obra el lugar neutro de la poesía de Macedonio.

11 Pero a la vez ese lugar lo preserva en el devenir de la poesía argentina. Porque si generacionalmente debió ser un modernista, su estética obró en dirección contraria y anticipatoria : la radical negación de la métrica y la rima suponía una negación de la ley de las semejanzas y la estética de la Analogía universal, aquella "sagrada Harmonía" que el modernismo sostuvo, desde Darío hasta Lugones. Del mismo modo, su entronización de la metáfora como centro del sistema evocaba la estética de los espejos de la vanguardia martinfierrista. Por cierto, su metafísica obró así como una metalengua del poema ultraísta : en el culto de la imagen, en la fusión de los polos sujeto y objeto, en la eliminación de todo elemento conectivo para crear complejos de sensaciones que puedan percibirse simultáneamente, en la busca de una emoción inédita e inventiva. Así Evar Méndez y todos sus coetáneos -Borges en especial- lo reconocieron.

La poesía de Macedonio no era modernista aunque tampoco, en rigor, vanguardista: porque si explícitamente se situaba en el polo opuesto a la estética de la analogía, la disolución o dispersión del sujeto imaginario de las vanguardias tampoco podía sostenerse en el lugar indecidible de la pasión amorosa que alienta la Poemática del Pensar y todo su mundo nocional, donde el sujeto no se desagrega sino se alterna en la dualidad de los Amantes. La subjetividad imaginaria de la poesía de Macedonio nunca es solipsista ni especular ni impersonal: es ayoica pero en la medida en que es un acontecimiento del Dos en el Todo-Misterio que adviene como proceso. ${ }^{3}$ Esa fluencia del Yo que es Ella, nunca de un otro que es el mismo, el borroso doble de los espejos: "La llamada 'doble personalidad' es mera verbalidad, mala denominación. Doble personalidad es una abstrusidad, un inconcebible ; pero el hecho de dos personas es auténtico" (2010: 98). Por ello la poesía de Macedonio alcanza un grado de extrañeza puramente discontinua respecto de una tradición discipular para los poetas argentinos : sus poemas del pensar dedicados a la Luna o a la Siesta no se parecen a nada. O sólo es el vago daguerrotipo de la actitud de la poesía de Alberto Girri o de textos igualmente radicales y enfáticamente excéntricos como los últimos "textos de sombra" o el Diario de Alejandra Pizarnik, algunos poemas de Osvaldo Lamborghini, El Himalaya o la moral de los pájaros de Miguel Ángel Bustos, Hospital Británico de Héctor Viel Temperley.

13 Así la poesía de Macedonio ocupa este lugar de lo neutro en la literatura argentina como esos hechos que al estremecer hacia el No-Ser todo lo que es, no pueden ser olvidados sino repetidos sin término. En esa imagen persistente Macedonio ha conseguido lo que quería : que seamos testigos de las cesaciones y recreaciones de Ella y Él en su eternidad ansiosa, esos dos fantasmas que se aman una y otra vez vueltos de la muerte, para que repitamos ahora el Poema que nadie olvidó en la caja de bizcochos y para que hablemos de ellos dos creyendo todavía que hablamos de literatura. 


\section{BIBLIOGRAFÍA}

Badiou, Alain. "Qué es el amor". En Condiciones. Buenos Aires : Siglo XXI Editores, 2002.

Barthes, Roland. Lo neutro. Buenos Aires : Siglo XXI Editores, 2004.

Blanchot, Maurice. El diálogo inconcluso. Caracas : Monte Ávila, 1970.

Calbi, Mariano. "La poesía de Macedonio Fernández". En : Roberto Ferro (Director del volumen). Macedonio. En : Noé Jitrik (Director). Historia crítica de la literatura argentina, vol. 8. Buenos Aires :

Emecé Editores, 2007, pp. 205-228.

Fernández, Macedonio. Poemas. México : Editorial Guarania, 1953.

Fernández, Macedonio. Papeles de Recienvenido. Edición de Adolfo de Obieta. Buenos Aires : Centro Editor de América Latina, 1966.

Fernández, Macedonio. No toda es vigilia la de los ojos abiertos y otros escritos. Edición de Adolfo de Objeta. Buenos Aires : Centro Editor de América Latina, 1967.

Fernández, Macedonio. Teorías. Edición de Adolfo de Obieta, Buenos Aires : Corregidor, 1974.

Fernández, Macedonio. Museo de la Novela de la Eterna. Edición crítica de Ana Camblong y Adolfo de Obieta, Archivos 25, ALLCA XX/ FCE, 1993.

Fernández, Macedonio. Relato, cuentos, poemas y misceláneas. Edición de Adolfo de Obieta. Buenos Aires : Corregidor, 2010.

Fernández Moreno, César. Introducción a Macedonio Fernández. Buenos Aires : Talía, 1960.

García, Germán. Macedonio Fernández : la escritura en objeto [1975]. Buenos Aires : Adriana Hidalgo editora, 2000.

Rigoli, Juan. "Devolución de la luna. Poesía y metafísica”. En : Roberto Ferro (Director del volumen). Macedonio. En : Noé Jitrik (Director). Historia crítica de la literatura argentina, vol. 8. Buenos Aires : Emecé Editores, 2007, pp. 229-260.

Vecchio, Diego. Egocidios : Macedonio Fernández y la liquidación del yo. Rosario : Beatriz Viterbo, 2003.

\section{NOTAS}

1. Testimonio oral de su hijo Adolfo de Obieta en una entrevista pública realizada por Esteban Peicovich, en el programa radial Los palabristas, Buenos Aires, realizada el 11 de junio de 1999. Puede escucharse la entrevista completa en las audiciones 9 y 10 del ciclo 2013 emitido por LS1 Radio de la Ciudad de Buenos Aires, AM 1110, de Los palabristas en el sitio www.peicovich.com/ audio/. Las referencias documentales que corrobora A. de Obieta pertenecen a esta entrevista.

2. Macedonio Fernández. Poemas. México: Editorial Guarania, 1953. Los poemas incluidos (obsérvese que "Tantalia" se presenta como poema, no como microrrelato) son los siguientes, en dos secciones :

I. Muerte es beldad : Manera de una psique sin cuerpo / Elena Bellamuerte / Muerta mimosa tuya quiero ser / Cuando nuestro dolor fíngese ajeno / A manos temblorosas / Hay un morir / 
Amor se fue / Creía yo / Palabras terminan / Otra vez / Es la Sombra en el día de Amor

II. Otros poemas : Dios visto, mi madre / Layda / Pasos en perdido / Poema de poesía del Pensar / Poema de trabajos de estudio de las estéticas de la siesta / Tantalia.

3. Tomo la noción de Alain Badiou porque hallo similitudes con este proceso que llama acontecimiento-encuentro de Dos y que, dice el filósofo francés, "el acontecimiento-encuentro no es sino la forma de su desaparición, de su eclipse”, modo igualmente paradójico tal como se lee en Macedonio. Afirma Badiou : "Para tener a la vez la disyunción y que haya verdad hace falta partir del amor como proceso, y no de la conciencia amorosa. Se postulará entonces que el amor es precisamente eso : el advenimiento del Dos como tal, la escena del Dos. Pero atención : esta escena del Dos no es un ser del Dos, lo cual supone el tres. Esta escena del Dos es un trabajo, un proceso. No existe sino como trayecto en la situación, bajo la suposición de que hay Dos". Véase Alain Badiou, “¿Qué es el amor ?” (2002 : 241-259).

\section{RESÚMENES}

Este ensayo vindica la figura de Macedonio Fernández como un "poeta recienvenido", que al mismo tiempo niega todo esencialismo autobiográfico y a la vez construye en el poema "Elena Bellamuerte" la transfiguración imaginaria de un hecho autobiográfico central : la muerte de su esposa Elena de Obieta. La poesía de Macedonio ocupa en su literatura el lugar de lo neutro, del latín ne-uter, ni lo uno ni lo otro, sino entre dos polos, en una posición indecidible. El carácter neutro de su poesía consiste en una radicalización a la vez del fantasma de la amada y la protesta y anulación de la muerte transfigurada en la ficción del poema, donde Elena es "la niña del fingido morir" y donde la muerte es negada por el amor, y es considerada "ocultación". La poesía es por ello un acto de Belarte Conciencial, donde se manifiesta lo neutro en lo imaginario : ni vida ni muerte, ni tú ni yo, ni ausencia ni presencia, ni momento ni lugar, ni uno ni otra sino entre dos términos, el lugar indecidible del Todo-Misterio que no se nombra, en espera de lo Eterno.

Cet article défend la figure de Macedonio Fernández en tant que "poeta recienvenido » (poète nouveau-venu) qui, tout en rejetant l'essentialisme autobiographique élabore cependant dans le poème «Elena Bellamuerte " la transfiguration imaginaire d'un épisode autobiographique : la mort de sa femme Elena de Obieta. La poésie macédonienne occupe dans sa littérature la place du neutre - du latin ne-uter, ni l'un ni l'autre, mais l'entre deux pôles, dans une position indécise-. Le caractère neutre de sa poésie réside à la fois dans la radicalisation du fantôme de l'aimée et dans une révolte contre la mort que le poème transfigure fictivement et cherche à annuler. Ici, Elena est « la niña del fingido morir » (la jeune fille de la fausse mort) et la mort elle-même est déniée par l'amour, et considérée comme «occultation». La poésie est donc une action de "Belarte Conciencial ", où le neutre se manifeste dans l'imaginaire : ni la vie ni la mort, ni toi ni moi, ni l'absence ni la présence, ni le temps ni le lieu, ni l'un ni l'autre, mais l'entre deux termes, c'est à dire, le lieu de l'indécidable Tout-Mystère qui n'est pas nommé, mais qui attend l'Eternel.

This essay vindicates Macedonio Fernández as a "poeta recienvenido", a "newcomer poet" that, at the same time, denies any autobiographical essentialism yet builds in the poem "Elena Bellamuerte" the imaginary transfiguration of a central autobiographical fact : the death of his wife Elena de Obieta. The poetry of Macedonio occupies in his literature the place of the neutral ( from the Latin ne-uter, neither one nor the other, but between two poles, in an undecided 
position). The neutral character of his poetry is both a radicalization of the ghost of the beloved and a protest and a cancellation of death transfigured by fiction in the poem, in which Elena is "la niña del fingido morir" (the fake dead girl) and death is denied by love, and is considered only an "occultation". Poetry is thus an act of "Belarte Conciencial", that manifests itself in the neutral imaginary: neither life nor death, neither you nor I, neither the absence nor the presence, neither time nor place, neither one nor the other but in between two terms, the undecided place where All-Mystery is not named, but is waiting for the Eternal.

\section{ÍNDICE}

Mots-clés: Macedonio Fernández, poésie argentine, le neutre

Palabras claves: Macedonio Fernández, poesía argentina, lo neutro

Keywords: Macedonio Fernández, argentine poetry, the neuter

\section{AUTOR}

\section{JORGE MONTELEONE}

CONICET / Instituto de Literatura Hispanoamericana (Universidad de Buenos Aires)

jorgejmonteleone@yahoo.com.ar 